Check for updates

Cite this: RSC Adv., 2018, 8, 4464

Received 18th October 2017

Accepted 26th December 2017

DOI: 10.1039/c7ra11503b

rsc.li/rsc-advances

\section{Study of oxidation of calcium sulfite in flue gas desulfurization by pore-type surface dielectric barrier discharge}

\author{
He Guo, (D) Nan Jiang, ${ }^{\text {ab }}$ Jie Li, ${ }^{\text {ab }}$ Xianjun Zhao, ${ }^{a}$ Yi Zhang, ${ }^{c}$ Chao Chen, ${ }^{c}$ \\ Hong Zhao, ${ }^{c}$ Changmin $\mathrm{Han}^{\mathrm{C}}$ and Yan Wuab
}

\begin{abstract}
Herein, a new pore-type surface dielectric barrier discharge (PSDBD) reactor was first used for the oxidation of calcium sulfite in flue gas desulfurization. The comparison of oxidation efficiency of calcium sulfite using air only oxidation, loop surface dielectric barrier discharge (LSDBD) oxidation, and PSDBD oxidation was carried out to account for the superiority of PSDBD oxidation. The feasibility of calcium sulfite oxidized by discharge plasma was first investigated, and then, the effect of energy density, power frequency, air flow rate, initial slurry concentration, slurry temperature, and slurry $\mathrm{pH}$ was explored. The results showed that it was feasible to oxidize calcium sulfite by discharge oxidation as compared to that by air only oxidation. Furthermore, the oxidation efficiency of calcium sulfite in a PSDBD reactor is higher than that in an LSDBD reactor. Higher frequency power, higher energy density, and higher air flow rate were beneficial for the oxidation of calcium sulfite. Higher oxidation efficiency could be obtained at a lower initial slurry concentration, higher slurry temperature, and lower slurry $\mathrm{pH}$, which could reach the highest values of $62.5 \%, 79.8 \%$, and $73.4 \%$ in the PSDBD reactor, respectively. The mechanism analysis illustrated that $\mathrm{O}_{3}$ played a major role during calcium sulfite oxidation.
\end{abstract}

\section{Introduction}

In recent years, people have suffered the deleterious effects of air pollution, and excessive emission of sulfur dioxide is one of the primary causes of this issue. Flue gas desulfurization technology, such as wet desulfurization, dry desulfurization, and semi-dry desulfurization, is becoming mature gradually at present. ${ }^{1-3}$ Among them, wet desulfurization is one of the most widely used methods for flue gas desulfurization, whose principle is to utilize limestone or lime slurry for assimilating sulfur dioxide from gas fume and then form calcium sulfite. ${ }^{4-6}$ The formed calcium sulfite is further oxidized, which then leads to the production of gypsum (calcium sulfate) that can be crystallized ultimately. The crystallized gypsum has high economic and nutritional value such as in building materials, papermaking, paving, etc. However, if calcium sulfite cannot be oxidized completely, sulfur dioxide can overflow again; this leads to secondary pollution. Furthermore, if the purity of gypsum is lower, the gypsum is unable to crystallize normally; this finally decreases the efficiency of desulfurization. Therefore, not only further oxidization of calcium sulfite from flue gas

${ }^{a}$ School of Environmental Science \& Technology, Dalian University of Technology, Dalian 116024, China. E-mail: Jiangnan@dlut.edu.cn

${ }^{b}$ School of Electrical Engineering, Dalian University of Technology, Dalian 116024, China

${ }^{c}$ Wuhan Kaidi Electric Power Environmental Co., Ltd., Wuhan 430223, China desulfurization can prevent the second overflow of sulfur dioxide, enhancing desulfurization efficiency, but also economically beneficial gypsum can be obtained.

There are many methods, such as forced oxidation, catalytic oxidation, and plasma oxidation, for oxidizing calcium sulfite. ${ }^{7-9}$ However, forced oxidation is affected by gas liquid mass transfer of oxygen, and lower utilization of oxygen, longer oxidation period, and limited lower concentration of calcium sulfite have restricted the development of this technology. Furthermore, the cost of equipment and energy consumption are higher. As for most catalysts, it is not easy to separate the catalyst from the slurry; thus, the constant addition of catalysts is required. Therefore, the solidification of catalysts becomes a key research topic. ${ }^{10-12}$ Fan and Fan have utilized ammoniacal leaching and ammonia chloride leaching to separate and recycle $\mathrm{Zn}^{2+}$ in a desulfurization slurry and obtained highly reactive $\mathrm{ZnO} .{ }^{10}$ Liu utilized the chemical precipitation method to separate $\mathrm{Cd}^{2+}$ in a desulfurization slurry. ${ }^{11}$ Brennan et al. adopted a process for removing catalyst fines from the wax product produced in a slurry Fischer-Tropsch reactor comprising removal of the wax product from the reactor and separation of the catalyst fines by passing the wax product through a high-gradient magnetic field. The separated catalyst fines can be returned to the reactor by backwashing the filter element. ${ }^{12}$ However, if the solidification of catalysts is considered, the whole catalytic oxidation process is complex and would increase the cost of desulfurization. 
Discharge plasma is one kind of advanced oxidation technology, with the generated active specials such as $\mathrm{O}_{3}, \mathrm{H}_{2} \mathrm{O}_{2}$, ${ }^{\circ} \mathrm{OH}$, and ${ }^{\circ} \mathrm{O}$, which have powerful oxidation ability to oxidize calcium sulfite faster and efficiently. ${ }^{13-16}$ The utilization of discharge plasma for calcium sulfite has been researched by our team., ${ }^{9,17,18}$ Xia et al. have explored plasma to oxidize calcium sulfite that not only can improve the oxidation efficiency of calcium sulfite but can also decrease the aeration rate and area of the slurry pond. ${ }^{9}$ Air activation for calcium sulfite oxidation by surface discharge was studied by Yao et al., and the oxidation efficiency of calcium sulfite by surface discharge was 1.5-1.7 times that of calcium sulfite treated by sole air oxidation. ${ }^{18}$ The method can reduce equipment investment and operation cost, which is of great significance for the improvement of the desulfurization process.

In the dielectric barrier discharge (DBD) process, different reactors can induce the injection of energy and the variation of physical effect and chemical effect such as electron energy, starting voltage, and the amount of active substances. Many researchers have introduced the LSDBD reactor for ozone generation and air pollution treatment. ${ }^{19-21}$ The advantage of this reactor is that discharge can occur in two areas with one electrode structure. The flue gas can be treated via two areas; this extends the discharge treatment time and enables flue gas treatment. However, there is only one low voltage electrode, and the high voltage electrode is set close to the inside wall of the quartz glass tube, which decreases the discharge intensity and leads to a lower concentration of the active substance. Furthermore, the area of the traditional reactor is larger in the case of same discharge length; this enhances the working area for treating calcium sulfite. Therefore, a new pore-type surface dielectric barrier discharge (PSDBD) was designed to investigate the oxidation of calcium sulfite in the study. The superiority of PSDBD on oxidizing calcium sulfite as compared to that of loop surface dielectric barrier discharge (LSDBD) and sole air oxidation was first investigated. Then, the effect of electric parameters (energy density, power type, and air flow rate) and slurry parameters (initial concentration, temperature, and $\mathrm{pH}$ ) were explored. Finally, the mechanism of calcium sulfite oxidation was explored. The study is of great importance in reducing the area of the reaction facility and enhancing desulfurization efficiency and gypsum quality.

\section{Experimental}

\subsection{Experimental apparatus}

The schematic of the experimental system is shown in Fig. 1. The system consists of a high voltage power source, an electrical detection system, a gas distribution system, a plasma reactor, and a calcium sulfite reactor; the operating frequency power and high frequency power sources were made by the Institute of Electrostatics and Special Power, Dalian University of Technology. The voltage is adjustable to $0-20 \mathrm{kV}$. The electrical detection system is made up of an oscilloscope (Tektronix TDS2024), a high-voltage probe (Tektronix P6015A), and a lowvoltage probe (Tektronix TPP0200). The gas distribution system comprised an air pump (HaiLi, ACO-318) and a flow meter (Kere LZB-6WB). The plasma reactor is shown in Fig. 2. Fig. 2(a) shows the pore-type surface reactor. The high voltage electrode is the aluminum foil with a round hole, the thickness and hole diameter of which are $0.05 \mathrm{~mm}$ and $70 \mathrm{~mm}$, respectively. The round hole of the aluminum foil is sealed by an insulating material to ensure discharge in the round hole. The dielectric material is a glass pane with a thickness of $1.5 \mathrm{~mm}$. The ground electrode is the aluminum foil, which is attached closely to the glass surface. The whole discharge area is cylindrical, and the high of the cylinder is the high of gas region. Fig. 2(b) shows the loop surface reactor. The high electrode is a stainless spring, whose wire diameter and screw pitch are $0.5 \mathrm{~mm}$ and $1.7 \mathrm{~m}$, respectively. The dielectric material is a glass tube with a thickness of $1.5 \mathrm{~mm}$ and an inner diameter of $12 \mathrm{~mm}$. The low electrode is the aluminum foil, which is attached tightly around the glass surface. The discharge length is $200 \mathrm{~mm}$. An organic glass and an aeration sand head constitute the calcium sulfite reactor. The inner diameter is $50 \mathrm{~mm}$, and the height of the organic glass is 1500 $\mathrm{mm}$.

\subsection{Experimental process and analytical methods}

Air was carried into the reactor by an air pump through the flow meter. The humidity of air was adjusted by bubbling a certain

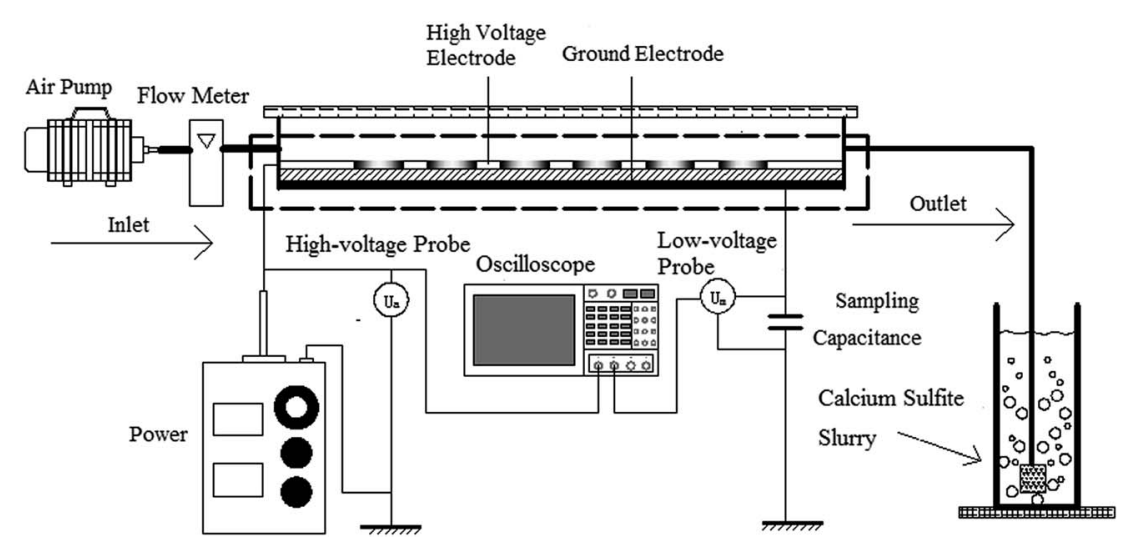

Fig. 1 The schematic of the experimental system. 


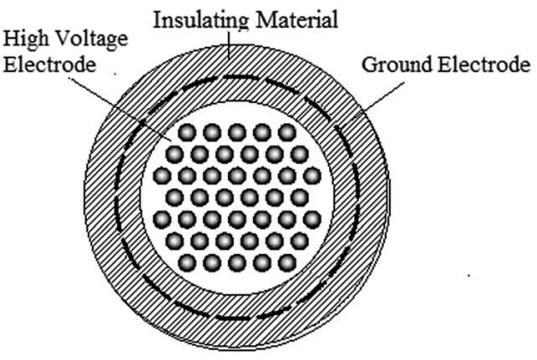

(a)

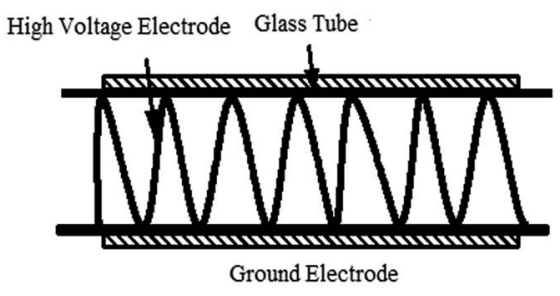

(b)

Fig. 2 The schematic of the experimental system: (a) the PSDBD reactor and (b) LSDBD reactor.

amount of vapor. The temperature of gas was controlled by a thermostatic water bath. The air temperature, relative humidity of air, and gas flow rate are $23{ }^{\circ} \mathrm{C}, 0$, and $1 \mathrm{~m}^{3} \mathrm{~h}^{-1}$, respectively. The concentration of ozone was measured using the iodometric method..$^{22}$ The slurry was prepared by deionized water and calcium sulfite, which was provided by the Tianjing Bodi Chemical Co., Ltd. Before preparation, deionized water was purged with argon to remove the dissolved oxygen. The initial $\mathrm{pH}$ value of the slurry is adjusted with $0.1 \mathrm{~mol} \mathrm{~L}^{-1} \mathrm{NaOH}$ and $0.1 \mathrm{~mol} \mathrm{~L}^{-1} \mathrm{HNO}_{3} \cdot \mathrm{H}_{2} \mathrm{O}_{2}$ concentration was measured using the titanium sulfate method. ${ }^{16}$ The concentration of calcium sulfite was determined using the iodometric method. ${ }^{23}$ The oxidation efficiency of calcium sulfite is calculated as follows:

$$
X_{t}(\%)=\frac{\left(C_{0}-C_{t}\right)}{C_{0}} \times 100 \%
$$

where $X_{t}$ is the oxidation efficiency of calcium sulfite; $C_{0}$ is the initial concentration of treated calcium sulfite, $\mathrm{mol} \mathrm{L}^{-1}$; and $C_{t}$ is the concentration of treated calcium sulfite at a discharge treatment time $t, \mathrm{~mol} \mathrm{~L}^{-1}$.

The specific energy density (SED) was measured as follows:

$$
\mathrm{SED}=\frac{P}{V} \times 60
$$

where SED is the specific energy density, $\mathrm{J} \mathrm{L}^{-1} ; P$ is the discharge

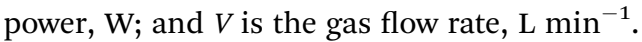

All the chemical reagents used in the study are of analytical pure grade. All data was tested two times, and the final values shown in the study are the average values.

\section{Results and discussion}

\subsection{The feasibility of calcium sulfite oxidized by discharge plasma}

To illustrate that SDBD is able to support the oxidation of calcium sulfite effectively, the efficiency of calcium sulfite oxidation by sole air aeration and surface discharge is compared in this study. The power used in the study was the operating frequency power with a frequency of $50 \mathrm{~Hz}$. The voltage was controlled at $19 \mathrm{kV}$, and the PSDBD and LSDBD have the same energy density. The result is shown in Fig. 3(a). In addition, to account for the advantage of PSDBD as compared to that of LSDBD, the ozone generation efficiency and energy utilization of calcium sulfite oxidation are given, shown in Fig. 3(b) and (c), respectively.

In Fig. 3(a), it can be seen that the oxidation efficiency via the three methods increases with an increase in oxidation time. With an oxidation time of $60 \mathrm{~min}$, the oxidation efficiency of calcium sulfite under sole air oxidation, LSDBD oxidation, and PSDBD oxidation could reach 52.3\%, 85.7\%, and $92.4 \%$, respectively. The increasing effect of SDBD was evident as compared to that of sole air oxidation; this illustrated that the generated ozone and other activated specials by SDBD could stimulate oxidation of calcium sulfite. It can also be seen that the oxidation efficiency in the PSDBD reactor is higher than that in the LSDBD reactor; this accounts for the superiority of PSDBD discharge on oxidizing calcium sulfite.

It can be seen from Fig. 3(b) that the ozone generation efficiency in the PSDBD system is higher than that in the LSDBD system under the same voltage; this can prove the superiority of PSDBD discharge on oxidizing calcium sulfite. It can also be found that with the increase in voltage, the ozone generation efficiency decreases regardless of the PSDBD system or LSDBD system. The highest ozone generation efficiency in the PSDBD system and LSDBD system is $53.36 \mu \mathrm{g} \mathrm{J} \mathrm{J}^{-1}$ and $30.17 \mu \mathrm{g} \mathrm{J} \mathrm{J}^{-1}$, respectively. The reason for this is that the increase in voltage can induce an enhancement of the discharge power that leads to an increase in the temperature. As a result, the higher temperature can induce the decomposition of ozone, which is not beneficial for the generation of ozone. In practical applications, energy utilization is an index for evaluating the efficiency of the system. The ozone production in the PSDBD system is higher under the same energy utilization. Moreover, to obtain a higher ozone production and ozone generation efficiency at the same time, we found that a voltage of $19 \mathrm{kV}$ could achieve a better effect.

It can be seen from Fig. 3(c) that as compared to the case of the LSDBD system, energy utilization of calcium sulfite oxidation is higher in the PSDBD system; this can illustrate the advantage of PSDBD oxidation. The highest energy utilization in the LSDBD system and PSDBD system can reach $7.22 \mathrm{~g} \mathrm{~J}^{-1}$ and $19.62 \mathrm{~g} \mathrm{~J}^{-1}$, respectively. In Fig. 3(c), it can be found that with an increase in time, the energy utilization of calcium sulfite oxidation decreases; this is because there is plenty of calcium sulfite that can react with the active species generated by DBD in 
(a)

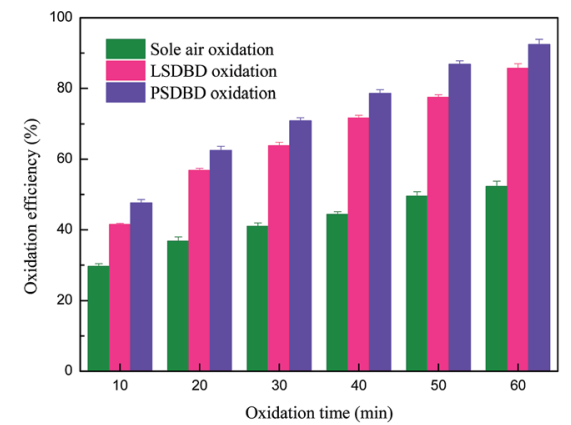

(b)

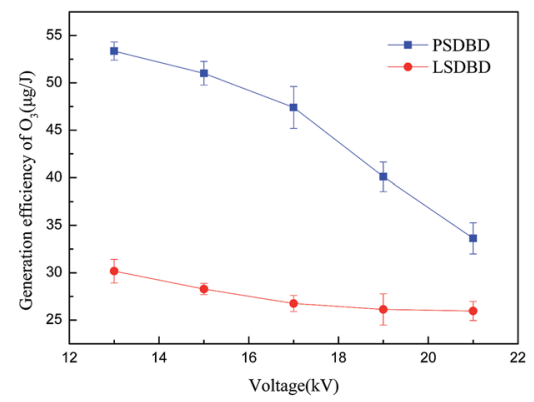

(c)

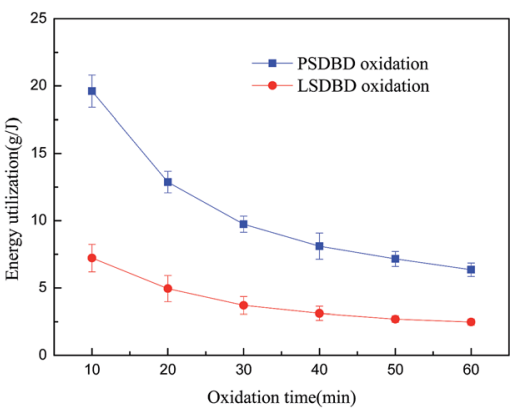

Fig. 3 (a) Efficiency of air aeration and surface discharge-induced calcium sulfite oxidation. (b) Generation efficiency of ozone by PSDBD and LSDBD. (c) Energy utilization of calcium sulfite oxidation by PSDBD and LSDBD.

the initial phase. As time goes by, there is not an excess of calcium sulfite consumed by active species; this accounts for the lower energy utilization in the later period.

\subsection{Effect of electric parameters on oxidation efficiency of calcium sulfite}

3.2.1 Effect of energy density of discharge on the oxidation efficiency of calcium sulfite. Energy density under different reactors can influence the generation of ozone and other active species and then lead to the variation of oxidation efficiency of calcium sulfite. Therefore, the effect of energy density on the oxidation efficiency of calcium sulfite is explored in the section. The result is shown in Fig. 4. For comparison, the oxidation efficiency of calcium sulfite under sole air oxidation is given as $37 \%$, as shown in our another study. ${ }^{\mathbf{2 4}}$

As shown in Fig. 4, with an increase in the energy density, the oxidation efficiency first increases and then reaches a plateau;

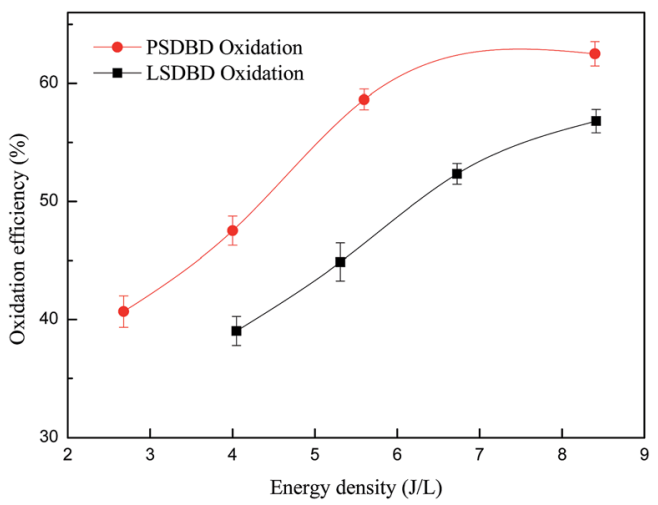

Fig. 4 Effect of different SED on the oxidation efficiency.

this is because the discharge intensity increases with the increase in energy density; this can promote the generation of more electrons, which induce more ozone production. The process of ozone generation is as follows:

$$
\begin{gathered}
\mathrm{O}_{2}+\mathrm{e}^{-} \rightarrow \cdot \mathrm{O}+{ }^{\cdot} \mathrm{O}+\mathrm{e}^{-} \\
\mathrm{O}_{2}+{ }^{\cdot} \mathrm{O} \rightarrow \mathrm{O}_{3}
\end{gathered}
$$

The oxidation efficiency of calcium sulfite under the twodischarge oxidation is higher than that under the sole air oxidation $(37 \%)$. In the case of the same energy density, the oxidation efficiency of calcium sulfite under PSDBD oxidation is higher than that under LSDBD oxidation. The oxidation efficiency of calcium sulfite under PSDBD oxidation and LSDBD oxidation can reach up to $62.5 \%$ and $56.8 \%$, respectively, when the energy density is $8.4 \mathrm{~J} \mathrm{~L}^{-1}$. The reason for it was that the generation efficiency of ozone in the PSDBD reactor was higher than that in the LSDBD reactor, as shown in Fig. 3(b). Therefore, more ozone can be generated in the PSDBD reactor, which can account for the higher oxidation efficiency of calcium sulfite. Because of the fixed mass transfer coefficient of ozone in the slurry, a greater amount of generated ozone was unable to be utilized efficiently and then overflowed when the energy density reached a certain value; this implied that the oxidation efficiency of calcium sulfite could not further increase at a higher energy density.

3.2.2 Effect of operating frequency power and high frequency power on oxidation efficiency of calcium sulfite. Power frequency can affect the energy input and in turn affect the generation of active substances, causing the change in the oxidation efficiency of calcium sulfite eventually. The effect of frequency was investigated, and the result is shown in Fig. 5. The frequency and voltage of high frequency power were controlled at $7 \mathrm{kHz}$ and $6 \mathrm{kV}$, respectively. From Fig. 5, it can be seen that over time, the oxidation efficiency of calcium sulfite in the reactor increases dramatically. The oxidation efficiency exceeded $70 \%$ at an oxidation time of $10 \mathrm{~min}$. As time went on, the variation in the trend of oxidation efficiency became smooth and slight. Almost all of the calcium sulfite was oxidized at less than 20 min of treatment time. 


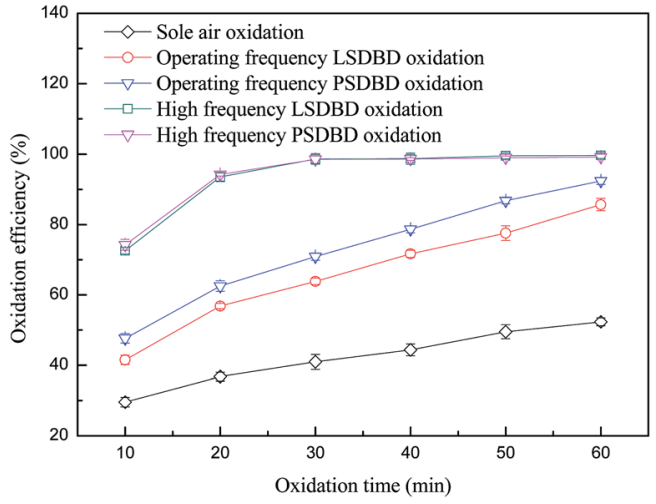

Fig. 5 Effect of operating frequency power and high frequency power on oxidation efficiency.

The reason for this was because the concentration of ozone generated by the high efficiency power was far higher than that generated by the operating frequency power; this made the oxidation efficiency of calcium sulfite increase rapidly. Furthermore, the concentration of ozone in the slurry reached saturation quickly; this led to the lower growth in the oxidation efficiency of calcium sulfite. Moreover, calcium sulfite was oxidized within a short time. It can also be seen from Fig. 5 that as compared to the operating frequency power, the oxidation efficiency of calcium sulfite can improve rapidly when using a high frequency power. However, the air temperature can increase when a high frequency power is used; this leads to ozone decomposition. As a result, the ozone generation efficiency at a high frequency power was considerably lower than that at the operating frequency power. Most of the energy was removed as heat, which is proved in our other study. ${ }^{24}$ In addition, a large amount of ozone was unable to be fully utilized and then overflowed from the slurry when a high frequency power was used. Herein, the utilization of energy has to be taken into account when high efficiency is employed in practical applications.

3.2.3 Effect of air flow rate on oxidation efficiency of calcium sulfite. The air flow rate not only affects the generation of active specials but also affects the retention time of gas in the slurry. The effect of air flow rate on the oxidation efficiency of calcium sulfite was therefore inspected, and the selected air flow rates were $0.7 \mathrm{~m}^{3} \mathrm{~h}^{-1}, 1 \mathrm{~m}^{3} \mathrm{~h}^{-1}$, and $1.4 \mathrm{~m}^{3} \mathrm{~h}^{-1}$. As shown in Fig. 6, the oxidation efficiency of calcium sulfite by the three methods increased to a certain extent. Compared to the case of discharge oxidation, the increase in the velocity of the oxidation efficiency by sole air oxidation is faster. At the same air flow rate, the order of oxidation efficiency of calcium sulfite in the three methods is as follows: PSDBD oxidation > LSDBD oxidation > sole air oxidation.

The reason for the result is that with regard to sole air oxidation, with the increasing air flow rate, the slurry is stirred sufficiently by gas and more of the generated ozone takes part in the oxidation of calcium sulfite; this leads to an increase in the oxidation efficiency. For the discharge oxidation, on the one hand, when the air flow rate increases to a certain value, a lot of

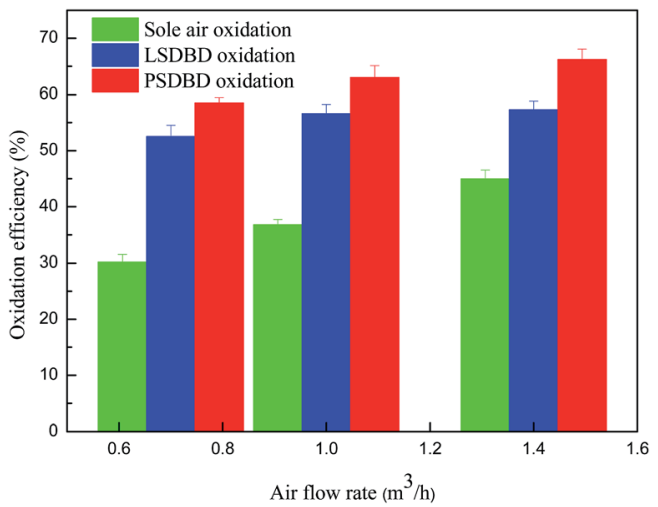

Fig. 6 Effect of air flow rate on oxidation efficiency.

air molecules fail to react with the free radicals and move away from the discharge area; this can induce a decline in the ozone concentration. On the other hand, when the air flow rate is higher, the gas-liquid in the slurry can be stirred without direction, and part of the bubble condenses into a large bubble, which can introduce a turbulent bubble phenomenon. The process makes more ozone flow out and leads to a loss of ozone. Therefore, the improvement of ozone generation was not apparent for a certain period; this accounted for the weak variation of the oxidation efficiency. It can also be seen that as compared to the LSDBD oxidation, the oxidation efficiency in the PSDBD reactor is higher, which illustrates the superiority of PSDBD.

\subsection{Effect of slurry parameter on the oxidation efficiency of calcium sulfite}

3.3.1 Effect of initial concentration of slurry on the oxidation efficiency and oxidation rate of calcium sulfite. The effect of the initial concentration of slurry on the oxidation efficiency and oxidation rate of calcium sulfite is shown in Fig. 7. The selected initial concentrations are $0.01 \mathrm{~mol} \mathrm{~L}^{-1}, 0.02 \mathrm{~mol} \mathrm{~L}^{-1}$, $0.05 \mathrm{~mol} \mathrm{~L}^{-1}$, and $0.07 \mathrm{~mol} \mathrm{~L}^{-1}$. Fig. 7(a) shows that the oxidation efficiency reduces nonlinearly with the increasing concentration of the slurry. The highest oxidation efficiency can be obtained when the concentration is $0.01 \mathrm{~mol} \mathrm{~L}^{-1}$. The oxidation efficiency of calcium sulfite treated by sole air oxidation, LSDBD oxidation, and PSDBD oxidation can reach about $37 \%, 57 \%$, and $62.5 \%$ respectively.

In Fig. 7(b), we can find that with the increase in the initial concentration, the oxidation rate increases for the three conditions. The reason for this can be that more active species contained or generated under the three conditions can collide and then react with calcium sulfite upon increasing the initial concentration of calcium sulfite. The utilization rate of the active species is higher, which can increase the oxidation rate. However, the amount of active species is a fixed value. When the initial concentration increases to a certain condition, there are not enough active species for oxidizing more calcium sulfite; this decreases the oxidation efficiency, as shown in Fig. 7(a).

Furthermore, calcium sulfite is slightly soluble in water. A higher concentration can induce calcium sulfite to precipitate 
(a)

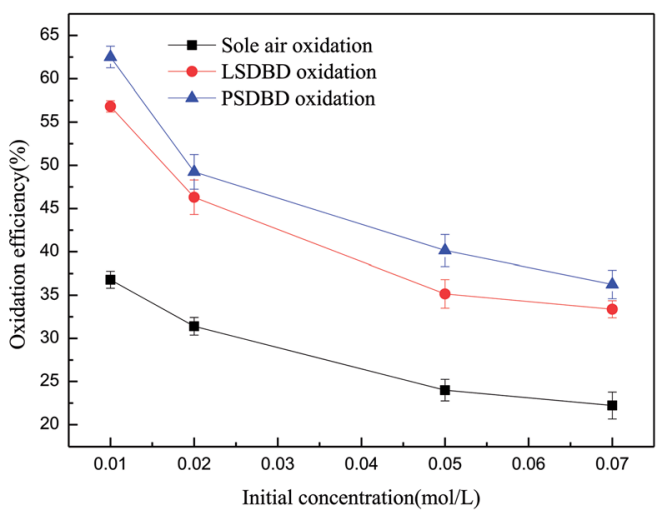

(b)

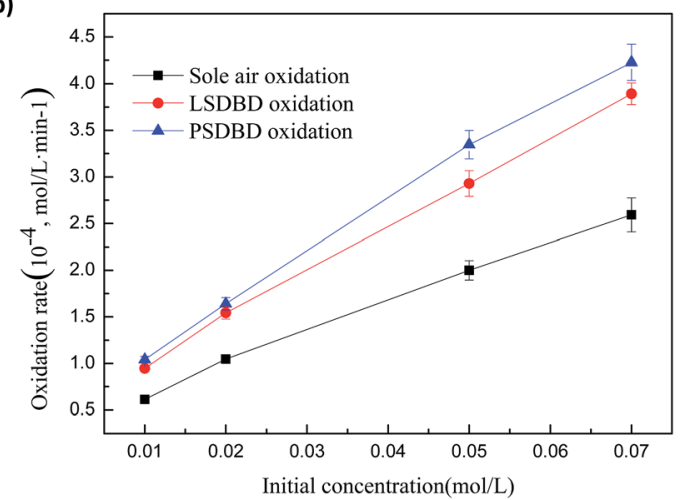

Fig. 7 (a) Effect of initial concentration of slurry on oxidation efficiency. (b) Effect of initial concentration of slurry on the oxidation rate.

out in the form of a suspension, causing the percentage of calcium sulfite oxidized to decline. It can also be seen that the oxidation efficiency of calcium sulfite first declines rapidly and then tends to flatten whether sole air oxidation or discharge oxidation is used in the study. It can be deduced that the amount of calcium sulfite oxidized in a higher concentration of slurry is greater than that oxidized in a lower concentration of slurry; this can be verified in Fig. 7(b). In addition, it was found that the oxidation rate obtained by PSDBD oxidation was higher as compared to that by LSDBD oxidation and sole air oxidation under the same concentration of slurry. It can be illustrated that the PSDBD oxidation can display superiority whether it is the oxidation efficiency or the oxidation rate.

3.3.2 Effect of slurry temperature on the oxidation efficiency of calcium sulfite. The solubility and stability of calcium sulfite in a slurry can be influenced by temperature. Thus, the effect of slurry temperature on the oxidation efficiency of calcium sulfite was investigated in the section. The slurry temperature was set as $23{ }^{\circ} \mathrm{C}, 40{ }^{\circ} \mathrm{C}, 50{ }^{\circ} \mathrm{C}$, and $60{ }^{\circ} \mathrm{C}$. The effect of the initial slurry temperature on the oxidation efficiency is shown in Fig. 8.

Fig. 8 indicates that a higher slurry temperature is beneficial for oxidizing calcium sulfite. The oxidation efficiency of calcium sulfite can improve above $20 \%$ under different oxidation methods when the temperature increases from $23{ }^{\circ} \mathrm{C}$ to $60{ }^{\circ} \mathrm{C}$. In the same case of temperature, the oxidation efficiency in the PSDBD reactor is highest, which can reach about $80 \%$ at

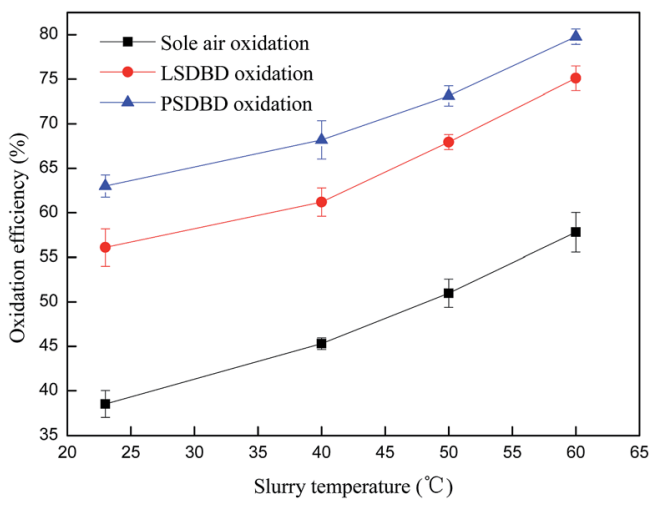

Fig. 8 Effect of initial slurry temperature on the oxidation efficiency.

a temperature of $60{ }^{\circ} \mathrm{C}$. However, the experiment also found that large quantities of sulfur dioxide leaked when the temperature exceeded $50{ }^{\circ} \mathrm{C}$.

The reason could be because the solubility of calcium sulfite was affected by temperature, and more calcium sulfite could be dissolved in solution and then be oxidized by oxygen and ozone. In addition, thermodynamics involves temperature, which leads to a higher oxidation rate at higher temperatures. The synthetic effect of the abovementioned two aspects increased the oxidation efficiency of calcium sulfite rapidly with the increasing slurry temperature. However, in the practical application process, on the one hand, the higher temperature is able to accelerate the decomposition of calcium sulfite, which leads to the overflow of sulfur dioxide and the decline of desulfurization efficiency; on the other hand, a higher temperature requires heating equipment, which can raise the energy consumption. Therefore, the slurry temperature should be controlled at below $50{ }^{\circ} \mathrm{C}$.

3.3.3 Effect of slurry $\mathrm{pH}$ on the oxidation efficiency of calcium sulfite. It is well known that the oxidation processes are very sensitive to the $\mathrm{pH}$ of the aqueous solutions. Fig. 9 shows the oxidation efficiency of calcium sulfite at different $\mathrm{pH}$ values of $3.5,4,4.5,5$, and 5.5. The oxidation efficiency of calcium sulfite declined nearly linearly with the increasing $\mathrm{pH}$ value gradually, whereas the whole decrease was below $10 \%$. Thus, it

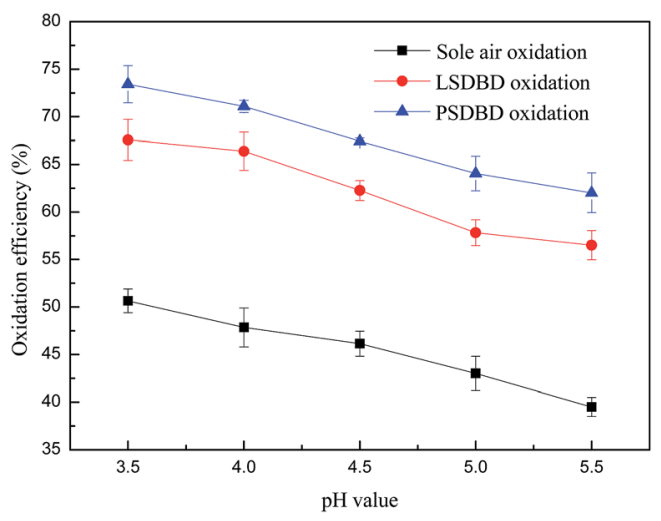

Fig. 9 Effect of the slurry $\mathrm{pH}$ value on oxidation efficiency. 
can be seen that the effect of slurry $\mathrm{pH}$ on the oxidation efficiency of calcium sulfite is weaker as compared to that of the slurry temperature. The highest oxidation efficiency of calcium sulfite could be achieved at a $\mathrm{pH}$ of 3.5 , and approximately $50.6 \%, 67.6 \%$, and $73.4 \%$ of calcium sulfite was oxidized by sole air oxidation, LSDBD oxidation, and PSDBD oxidation. Obviously, calcium sulfite was easiest to be oxidized by PSDBD oxidation at the same slurry $\mathrm{pH}$ value.

The reason for the result was that the solubility of calcium sulfite was affected by the slurry $\mathrm{pH}$ value. A higher solubility of calcium sulfite and faster mass transfer could be achieved at a lower $\mathrm{pH}$ value, promoting the oxidation reaction between the active species and calcium sulfite. However, a lower $\mathrm{pH}$ value was conducive to the decomposition of $\mathrm{HSO}_{3}{ }^{-}$and led to the overflow of sulfur dioxide, which decreased the desulfurization efficiency. In this study, we found that an overflow of sulfur dioxide could appear when the $\mathrm{pH}$ value was about 4 . To obtain a higher oxidation rate and reduce the release of sulfur dioxide as far as possible, the slurry $\mathrm{pH}$ ought to be controlled to about 5.0 in practical applications.

\subsection{Reaction mechanism analysis}

During the process of DBD in the gas phase, many active species can be generated such as $\mathrm{O}_{3},{ }^{\circ} \mathrm{O}$, and ${ }^{\circ} \mathrm{N}$. Among these active species, $\mathrm{O}_{3}$ is long-lived, which can transport to a certain distance. In this study, the generated $\mathrm{O}_{3}$ from the DBD reactor is used to bubble into the slurry and oxidize calcium sulfite. During the oxidation, one the on hand, $\mathrm{O}_{3}$ can be involved in the oxidation reactions directly. The reaction process can be listed as follows: ${ }^{25}$

$$
\begin{gathered}
\mathrm{CaSO}_{3} \cdot \frac{1}{2} \mathrm{H}_{2} \mathrm{O}(\mathrm{s}) \rightarrow \mathrm{CaSO}_{3}(\mathrm{aq})+\frac{1}{2} \mathrm{H}_{2} \mathrm{O} \\
\mathrm{CaSO}_{3}(\mathrm{aq}) \rightarrow \mathrm{Ca}^{2+}+\mathrm{SO}_{3}{ }^{2-} \\
\mathrm{H}^{+}+\mathrm{SO}_{3}{ }^{2-} \rightarrow \mathrm{HSO}_{3}^{-} \\
\mathrm{HSO}_{4}{ }^{-}+2 \mathrm{O}_{3} \rightarrow \mathrm{SO}_{4}{ }^{2-}+\mathrm{H}^{+}+3 \mathrm{O}_{2} \\
\mathrm{SO}_{3}{ }^{2-}+\mathrm{O}_{3} \rightarrow \mathrm{SO}_{4}{ }^{2-}+\mathrm{O}_{2}
\end{gathered}
$$

The solubility of calcium sulfite in water is extremely low. At a higher $\mathrm{pH}$ value, the concentration of $\mathrm{SO}_{3}{ }^{2-}$ provided by eqn (6) is extremely low, and the oxidation rate is very slow. With the decline in the $\mathrm{pH}$ value, the solubility of calcium sulfite increases quickly, the generation rate of $\mathrm{HSO}_{4}{ }^{-}$becomes rapid, and then, the concentration of $\mathrm{HSO}_{4}{ }^{-}$increases further. In practical oxidation, the oxidation process follows eqn (7). The $\mathrm{H}^{+}$generated by eqn (8) can participate in the reaction of eqn (7) circularly and convert $\mathrm{SO}_{4}{ }^{-}$to $\mathrm{HSO}_{4}{ }^{-}$, which can prevent the serious overflow of $\mathrm{SO}_{2}$. Before the experiment, the $\mathrm{pH}$ value was adjusted. Herein, the $\mathrm{pH}$ value did not decline any time during the experiment. When the initial $\mathrm{pH}$ value is very low, calcium sulfite can decompose by itself, and the reaction of eqn (7) is limited. Therefore, in practical applications, the $\mathrm{pH}$ value should be controlled to about 5 , which can maintain a higher solubility of calcium sulfite and prevent its serious decomposition at the same time.

On the other hand, $\mathrm{O}_{3}$ can participate in the oxidation reactions directly and initiate the free radical chain reaction. The process of the free radical chain reaction is listed as follow:

$$
\begin{aligned}
& \mathrm{O}_{3}+\mathrm{OH}^{-} \rightarrow \mathrm{HO}_{2}^{\cdot}+{ }^{\cdot} \mathrm{O}_{2} \\
& \mathrm{HO}_{2}{ }^{\cdot} \rightarrow \mathrm{O}_{2}^{-}+\mathrm{H}^{+} \\
& \mathrm{O}_{3}+{ }^{\cdot} \mathrm{O}_{2} \rightarrow \mathrm{O}_{3}^{-\cdot}+\mathrm{O}_{2} \\
& \mathrm{O}_{3}{ }^{-\cdot}+\mathrm{H}^{+} \rightarrow \mathrm{HO}_{3}{ }^{\cdot} \\
& \mathrm{HO}_{3}^{\cdot} \rightarrow \cdot \mathrm{OH}+\mathrm{O}_{2} \\
& \cdot \mathrm{OH}+\cdot \mathrm{OH} \rightarrow \mathrm{H}_{2} \mathrm{O}_{2} \\
& \cdot \mathrm{OH}+\mathrm{O}_{3} \rightarrow \mathrm{HO}_{4}{ }^{\cdot} \\
& \mathrm{HO}_{4}{ }^{\cdot} \rightarrow \mathrm{HO}_{2}{ }^{+}+\mathrm{O}_{2} \\
& \mathrm{HO}_{4}{ }^{\circ}+\mathrm{HO}_{4}{ }^{\cdot} \rightarrow \mathrm{H}_{2} \mathrm{O}_{2}+2 \mathrm{O}_{3} \\
& \mathrm{HO}_{4}{ }^{\cdot}+\mathrm{HO}_{3}^{\cdot} \rightarrow \mathrm{H}_{2} \mathrm{O}_{2}+\mathrm{O}_{3}+\mathrm{O}_{2} \\
& \mathrm{HO}_{4}{ }^{\cdot}+\mathrm{HO}_{2}{ }^{\cdot} \rightarrow \mathrm{H}_{2} \mathrm{O}+\mathrm{O}_{3}+\mathrm{O}_{2} \\
& \mathrm{SO}_{3}{ }^{2-} \stackrel{\text { free radicals }}{\longrightarrow} \mathrm{SO}_{3}{ }^{-} \\
& \mathrm{SO}_{3}{ }^{-}+\mathrm{O}_{2} \rightarrow \mathrm{SO}_{5}{ }^{-} \\
& \mathrm{SO}_{5}{ }^{-}+\mathrm{SO}_{3}{ }^{-} \rightarrow \mathrm{SO}_{4}{ }^{2-}+\mathrm{SO}_{4}{ }^{-} \\
& \mathrm{SO}_{4}{ }^{-}+\mathrm{HSO}_{3}{ }^{-} \rightarrow \mathrm{HSO}_{4}{ }^{-}+\mathrm{SO}_{3}{ }^{-} \\
& \mathrm{SO}_{5}{ }^{-}+\mathrm{SO}_{5}{ }^{-} \rightarrow \mathrm{S}_{2} \mathrm{O}_{8}{ }^{2-}+\mathrm{O}_{2}
\end{aligned}
$$

During these reactions, eqn (21) is the chain-initiating step, the eqn (22) is the chain-transfer step, and eqn (25) is the chaintermination step. The free radicals, such as ${ }^{\circ} \mathrm{O},{ }^{\circ} \mathrm{O}_{2}$, and ${ }^{\circ} \mathrm{OH}$ are produced from the soluble ozone generated by DBD. These free radicals have a strong ability of oxidation, which can improve the oxidation efficiency of calcium sulfite.

To verify the role of $\mathrm{O}_{3}$ and ${ }^{\circ} \mathrm{OH}$ during the calcium sulfite oxidation, the concentrations of dissolved ozone in deionized water and slurry were detected. The existence time of ${ }^{\circ} \mathrm{OH}$ is extremely short, and ${ }^{\circ} \mathrm{OH}$ can form $\mathrm{H}_{2} \mathrm{O}_{2}$ quickly, as shown in eqn (15). The production of $\mathrm{H}_{2} \mathrm{O}_{2}$ can indirectly represent the amount of ${ }^{\circ} \mathrm{OH}{ }^{14}$ Therefore, the productions of $\mathrm{H}_{2} \mathrm{O}_{2}$ in deionized water and slurry were detected to illustrate the effect of ${ }^{\circ} \mathrm{OH}$. The voltage is set as $19 \mathrm{kV}$. The variation of $\mathrm{O}_{3}$ and $\mathrm{H}_{2} \mathrm{O}_{2}$ concentration in deionized water and slurry is shown in Fig. 10.

In Fig. 10, it can be seen that as compared to that of $\mathrm{O}_{3}$, the concentration of $\mathrm{H}_{2} \mathrm{O}_{2}$ is lower both in deionized water and slurry; this indicates that $\mathrm{O}_{3}$ is the major active species in the aqueous solution. The concentration of $\mathrm{O}_{3}$ in deionized water is higher than that in the slurry; this can account for the oxidation effect of $\mathrm{O}_{3}$. The consumption and utilization of $\mathrm{O}_{3}$ were 


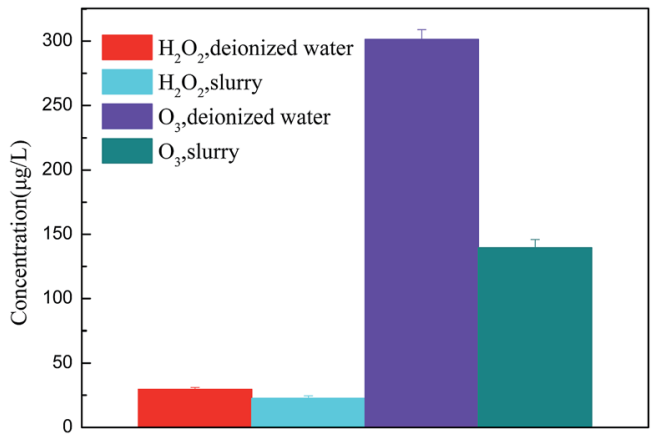

Fig. 10 The variation of $\mathrm{O}_{3}$ and $\mathrm{H}_{2} \mathrm{O}_{2}$ concentration in deionized water and slurry.

calculated as $161.77 \mu \mathrm{g} \mathrm{L}^{-1}$ and $53.68 \%$, respectively. Similarly, the concentration of $\mathrm{H}_{2} \mathrm{O}_{2}$ in deionized water is higher than that in the slurry; this can account for the oxidation effect of ${ }^{\circ} \mathrm{OH}$. However, the consumption and utilization of $\mathrm{H}_{2} \mathrm{O}_{2}$ were calculated as $6.94 \mu \mathrm{g} \mathrm{L}^{-1}$ and $23.50 \%$, which were much less than $161.77 \mu \mathrm{g} \mathrm{L}^{-1}$ and $53.68 \%$ of $\mathrm{O}_{3}$, respectively. Therefore, it can be demonstrated that the direct oxidation of $\mathrm{O}_{3}$ plays a major role during calcium sulfite oxidation.

\section{Conclusion}

In the study, a new PSDBD reactor was designed to investigate the oxidation of calcium sulfite. It was beneficial to oxidize calcium sulfite by adopting discharge oxidation rather than sole air oxidation. The oxidation efficiency of calcium sulfite in the PSDBD reactor was higher than that in the LSDBD reactor; this indicated the superiority of PSDBD oxidation. The oxidation efficiency of calcium sulfite first increased and then plateaued with the increasing energy density. A higher oxidation efficiency of calcium sulfite could be obtained with a high efficiency power and a higher gas flow rate. A lower initial slurry concentration, higher slurry temperature, and lower slurry $\mathrm{pH}$ contributed to the oxidation of calcium sulfite. The PSDBD reactor was beneficial for calcium sulfite oxidation with respect to LSDBD under the abovementioned operation parameters; this demonstrated that the adopted PSDBD discharge was advantageous for calcium sulfite oxidation. Compared to free radical oxidation, the direct oxidation of $\mathrm{O}_{3}$ played a major role during calcium sulfite oxidation.

\section{Conflicts of interest}

There are no conflicts to declare.

\section{Acknowledgements}

We would like to thank Wuhan Kaidi Electric Power for their financial support to this work.

\section{References}

1 H. G. Nygaard, S. Kiil, J. E. Johnsson, J. N. Jensen, J. Hansen, F. Fogh and K. Dam-Johansen, Fuel, 2004, 83, 1151-1164.

2 F. F. Hill and J. Zank, Chem. Eng. Process., 2000, 39, 45-52.

3 T. Zaremba, A. Dukowicz, J. Hehlmann, W. Mokrosz, E. Kujawska and J. Therm, Anal. Calorim., 2003, 74, 503-510.

4 S. Kiil, M. L. Michelsen and K. Dam-Johansen, Ind. Eng. Chem. Res., 1998, 37, 2792-2806.

5 F. J. Gutiérrez Ortiz, F. Vidal, P. Ollero, L. Salvador, V. Cortés and A. Gimenez, Ind. Eng. Chem. Res., 2006, 45, 1466-1477.

6 R. Meij, Water, Air, Soil Pollut., 1991, 56, 21-33.

7 C. H. Peng and Z. Q. Dong, J. China Inst. Metro., 2002, 13, 139-143.

8 Y. Li, J. Zhou, T. Zhu and P. Jing, Waste Biomass Valorization, 2014, 5, 125-131.

9 Y. Xia, X. M. Yao, Y. Zhang, K. F. Shang, J. Li and Y. Wu, High Voltage Engineering, 2016, 42, 2683-2684.

10 J. Fan and B. Fan, HeiLongjiang Oil. Chem., 1998, 9, 15-17.

11 Z. B. Liu, Masters thesis, Beijing University of Chemical Technology, 2010.

12 J. A. Brennan, A. W. Chester and Y. F. Chu, US4605678, 1986.

13 H. Guo, H. J. Wang, Q. S. Wu, G. S. Zhou and C. W. Yi, Chemosphere, 2016, 159, 221-227.

14 H. J. Wang, H. Guo, Q. S. Wu, G. S. Zhou and C. W. Yi, Vacuum, 2016, 128, 99-105.

15 N. Jiang, N. Lu, K. F. Shang, J. Li and Y. Wu, Environ. Sci. Technol., 2013, 47, 9898-9903.

16 H. J. Wang, H. Guo, Y. J. Liu and C. W. Yi, IEEE Trans. Plasma Sci., 2016, 44, 1834-1841.

17 C. M. Han, Y. Zhang, K. F. Shang, S. Wu, J. Li and Y. Wu, J. Environ. Eng., 2015, 9, 3566-3569.

18 X. M. Yao, Y. Xia, Y. Zhang, H. Zhao, J. Li and Y. Wu, China Inst. Phys, 19th National Conf. Electrostat. Acad., 2014.

19 Y. Zhang, L. H. X. Li, J. Li, S. Yue, K. F. Shang and Y. Wu, High Voltage Engineering, 2015, 41, 539-546.

20 S. Yue, Masters thesis, Dalian University of Technology, 2015.

21 N. Jiang, N. Lu, J. Li and Y. Wu, Plasma Sci. Technol., 2012, 14, 140-146.

22 K. Rakness, G. Gordon, B. Langlais, W. Masschelein, N. Matsumoto, Y. Richard, C. M. Robson and I. Somiya, Ozone: Sci. Eng., 1996, 18, 209-229.

232000 H J T., State Environmental Protection Administration, HJ/T56-2000, 2000.

24 X. J. Zhao, Masters thesis, Dalian University of Technology, 2016.

25 L. D. Zhang, D. Y. Qian and C. Y. Song, J. Univ. Sci. Technol. Beijing, 2011, 33, 1204-1208. 